\title{
Radical zinc-atom-transfer-based carbozincation of haloalkynes with dialkylzincs
}

\author{
Fabrice Chemla*, Florian Dulong, Franck Ferreira \\ and Alejandro Pérez-Luna*
}

Open Access

\author{
Full Research Paper \\ Address: \\ Institut Parisien de Chimie Moléculaire (UMR 7201), FR 2769, UPMC \\ Univ Paris 06, CNRS, Bâtiment F 2ème et., Case 183, 4 place \\ Jussieu, F-75005 Paris, France \\ Email: \\ Fabrice Chemla* - fabrice.chemla@upmc.fr; Alejandro Pérez-Luna* - \\ alejandro.perez_luna@upmc.fr \\ * Corresponding author \\ Keywords: \\ carbenoids; carbometallation; carbozincation; radicals; tandem \\ reaction
}

\author{
Beilstein J. Org. Chem. 2013, 9, 236-245. \\ doi:10.3762/bjoc.9.28 \\ Received: 13 November 2012 \\ Accepted: 08 January 2013 \\ Published: 04 February 2013 \\ This article is part of the Thematic Series "Carbometallation chemistry". \\ Guest Editor: I. Marek \\ (c) 2013 Chemla et al; licensee Beilstein-Institut. \\ License and terms: see end of document.
}

\begin{abstract}
The formation of alkylidenezinc carbenoids by 1,4-addition/carbozincation of dialkylzincs or alkyl iodides based on zinc atom radical transfer, in the presence of dimethylzinc with $\beta$-(propargyloxy)enoates having pendant iodo- and bromoalkynes, is disclosed. Formation of the carbenoid intermediate is fully stereoselective at $-30{ }^{\circ} \mathrm{C}$ and arises from a formal anti-selective carbozincation reaction. Upon warming, the zinc carbenoid is stereochemically labile and isomerizes to its more stable form.
\end{abstract}

\section{Introduction}

The last few years have witnessed a gaining interest in the use of organozinc reagents as nontoxic radical precursors or mediators [1-3]. As part of this development, the so-called radicalpolar reactions in which alkylzinc reagents are used as mediators in a radical transformation that affords a new zincated species, have emerged as valuable tools in synthesis. Pivotal to the processes disclosed so far using alkylzinc derivatives is zinc atom radical transfer [4]. In general terms, the reaction involves a radical chain process initiated by the formation of an alkyl radical from the organozinc derivative in the presence of oxygen [5-14]. The newly formed radical then undergoes one or more radical transformations before being reduced by the alkylzinc reagent through homolytic substitution at zinc, producing a new organozinc derivative along with an alkyl radical that sustains a radical chain. Overall, the in situ transformation of simple organozinc reagents into more elaborate ones is thus achieved, and subsequent reaction with electrophiles is possible [15-30].

More specifically, building on well-established addition reactions of carbon-centered radicals to carbon-carbon double and triple bonds, such reactivity has been advantageously employed in the context of carbozincation chemistry [31]. The intramolecular carbozincation of unactivated terminal alkenes following zinc atom transfer processes, including a 5-exo-trig cyclization step, has been reported. This is, for instance, the case in the for- 
mation of (pyrrolidylmethyl)zinc and (tetrahydrofuranylmethyl)zinc derivatives by reaction of dialkylzinc, organozinc and copper-zinc mixed reagents with $(N$-allyl)aminoenoates [32-34] and $\beta$-(allyloxy)enoates [35], in the formation of (pyrrolidonylmethyl)zinc by condensation of dialkylzincs with $N, N$-diallylpropiolamide [36], and also in the cyclization of alkenylzinc iodides to cyclopentylmethylzinc iodides, formerly believed to be anionic in nature [4]. Carbozincations of alkynes based on zinc atom transfer have also been disclosed. The reaction of dialkylzincs or of alkyl iodides in the presence of $\mathrm{Me}_{2} \mathrm{Zn} / \mathrm{O}_{2}$ with $\beta$-(propargyloxy)enoates entails the intramolecular carbometallation of the pendant alkynes substituted by silyl, alkyl, aryl, alkenyl or amino groups by a 5-exo dig radical cyclization step [37,38]. Intermolecular carbozincation of terminal arylacetylenes [39] and of diethyl acetylenedicarboxylate [40] has been achieved by dialkylzinc-mediated radical additions. Worthy of note is that in some cases the zinc-atomtransfer-based carbozincation of alkynes can occur with anti selectivity $[38,40]$, and thereby represents a complementary approach to transition-metal-mediated carbozincations, which are generally syn-selective [41-46].

To explore further the possibilities offered by zinc atom transfer processes we considered the possibility to prepare alkylidenezinc carbenoids by radical-based carbozincation of haloalkynes. Such carbenoids are multipurpose reagents [47] that are typically prepared from 1,1'-dihaloalkenes, either by lithium/halogen exchange followed by transmetallation with zinc salts or by direct zinc/halogen exchange [48-50]. Alternatively, they can also be prepared efficiently by selective monohalogenation of alkylidene gem-bismetallic intermediates [51].

To the best of our knowledge, the preparation of alkylidenezinc carbenoids by the direct carbozincation of haloalkynes has not been reported [52]. As a starting point to develop such an approach, we reasoned that the reaction of dialkylzincs with $\beta$-(propargyloxy)enoates bearing pendant haloalkynes would be ideally suited (Scheme 1). On the one hand it would provide a means to control totally the regioselectivity of the radical addition to the haloalkyne, and on the other hand the envisioned zinc atom transfer to an $\alpha$-halo vinylic radical should be favorable as a result of the presence of the ester moiety. Hereafter, we disclose our findings concerning this reaction.

\section{Results and Discussion}

$\beta$-(Propargyloxy)enoates $\mathbf{3 a}$ and $\mathbf{3 b}$ having a pendant bromoalkyne and an iodoalkyne moiety, respectively, were prepared by condensation of propargylic alcohols 1 with methyl 2-(bromomethyl)acrylate (2) (Scheme 2). Enoate 3a was readily obtained by direct reaction of 3-bromopropargyl alcohol (1a).

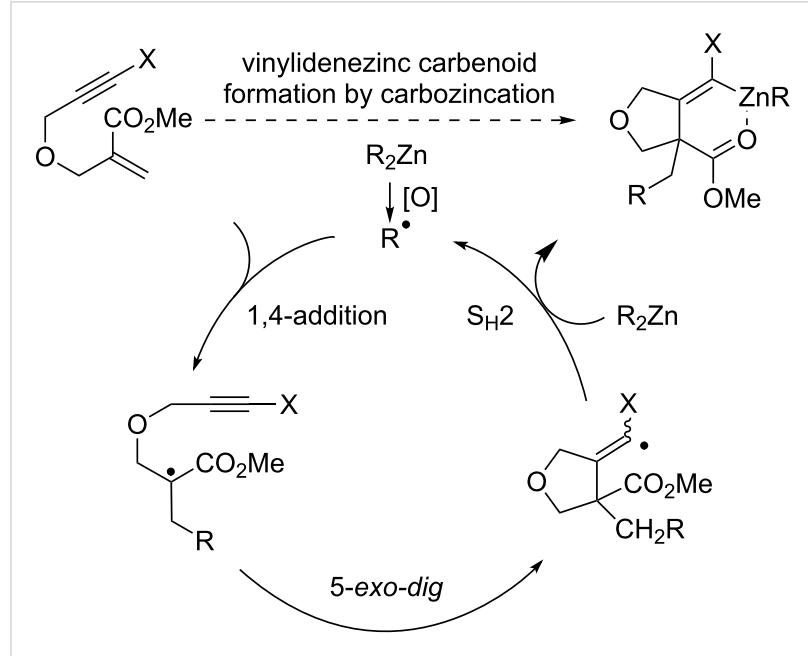

Scheme 1: Anticipated formation of alkylidene zinc carbenoids by reaction of dialkylzincs with $\beta$-(propargyloxy)enoates having pendant haloalkynes.

By contrast, the reaction of the iodo analogue $\mathbf{1 b}$ with $\mathbf{2}$ proved troublesome as it led to inseparable mixtures of the desired enoate $\mathbf{3 b}$ and non-iodinated enoate $\mathbf{3 c}$. Thus, $\mathbf{3 b}$ was best prepared by iodinating $\left(\mathrm{AgNO}_{3} / \mathrm{NIS}\right)$ the terminal alkyne of enoate $3 \mathbf{c}$ prepared from propargyl alcohol (1c) and acrylate 2 .

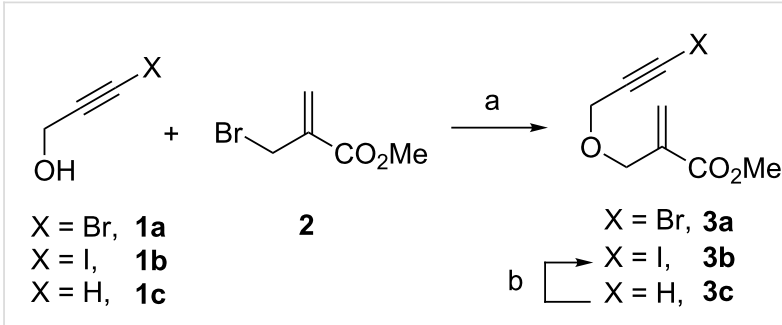

Scheme 2: Preparation of $\beta$-(propargyloxy)enoates having pendant haloalkynes. Reagents and conditions: (a) 2 (1.4 equiv), $\mathrm{Et}_{3} \mathrm{~N}$ (4 equiv), $\mathrm{Nal}(10 \mathrm{~mol} \%), \mathrm{CH}_{2} \mathrm{Cl}_{2}, 50{ }^{\circ} \mathrm{C}$, sealed tube, $74 \%$ (3a), $87 \%$ (3c); (b) $\mathrm{AgNO}_{3}$ (1.5 equiv), $\mathrm{N}$-iodosuccinimide (1.5 equiv), acetone, rt, $53 \%(3 b)$.

According to our previously optimized conditions for the 1,4addition/carbozincation reaction of dialkylzincs with $\beta$-(propargyloxy)enoates [37,38], bromoalkyne 3a was treated with $\mathrm{Et}_{2} \mathrm{Zn}$ at room temperature in $\mathrm{Et}_{2} \mathrm{O}$ under an argon atmosphere (Table 1, entry 1). To our delight, following acidic work-up, the expected methylenetetrahydrofuranyl bromide $4 \mathbf{a a}$ was obtained in $43 \%$ isolated yield as a mixture of diastereoisomers in a 77:23 $Z / E$ ratio [53]. Hydrolysis with $\mathrm{D}_{2} \mathrm{O}$ evidenced the intermediate formation of an alkylidene zinc carbenoid as deuterated 4aa-D was produced (Table 1, entry 2). As previously noted in the case of similar 1,4-addition/carbozincation sequences $[37,38]$, deuterium incorporation was nearly quantitative for the $Z$ isomer, and much lower for the $E$ one. More 
Table 1: 1,4-addition/carbozincation of dialkylzincs with $\beta$-(propargyloxy)enoates 3 having pendant haloalkynes in the presence of traces of air. ${ }^{a}$<smiles>[X]C#CCOCC(=C)OC</smiles>

3

3a $(\mathrm{X}=\mathrm{Br})$

$3 \mathbf{b}(X=I)$

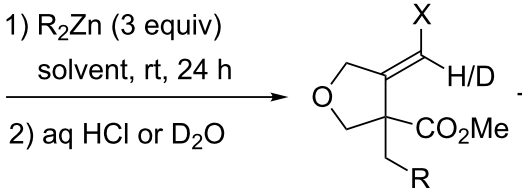

(Z)-4<smiles>[R]CC1(C(=O)O)COCC1=C([O-])[O-]</smiles>

$(E)-4$<smiles>[R]CC1(C(=O)O)COC/C1=C(/[R])[OH2+]</smiles>

(Z)-5<smiles>[R]CC1(C(C)=O)COC/C1=C(\[R])[O-]</smiles>

$(E)-5$

4aa $(X=B r, R=E t)$

4ba $(X=I, R=E t)$

$5 a(R=E t)$

4ab $(X=B r, R=B u)$

$5 \mathbf{b}(\mathrm{R}=\mathrm{Bu})$

4bb $(X=I, R=B u)$

\begin{tabular}{|c|c|c|c|c|c|}
\hline Entry & Enoate & $x$ & Solvent & $\mathrm{R}$ & Products (Yield $\left.{ }^{\mathrm{b}}(\%)\left[\mathrm{dr}^{\mathrm{c}}(\mathrm{Z} / E)\right]\right)$ \\
\hline 1 & $3 a$ & $\mathrm{Br}$ & $\mathrm{Et}_{2} \mathrm{O}$ & Et & 4aa (43 [77:23]); $5 \mathbf{a}(40$ [79:21]) \\
\hline 2 & $3 \mathbf{a}$ & $\mathrm{Br}$ & $\mathrm{Et}_{2} \mathrm{O}$ & Et & $\begin{array}{l}\text { 4aa-D }{ }^{d}(44[81(90 \% \text { D): } 19(10 \% \text { D)] }) \\
\text { sa-D }^{d}(35[84(85 \% \text { D):16(40\% D)] })\end{array}$ \\
\hline 3 & $3 b$ & I & $\mathrm{Et}_{2} \mathrm{O}$ & Et & 4ba $\left(40^{\mathrm{e}}[98: 2]\right) ; 5 \mathrm{a}\left(21^{\mathrm{e}}[82: 18]\right)$ \\
\hline 4 & $3 a$ & $\mathrm{Br}$ & $\mathrm{Et}_{2} \mathrm{O}$ & $n-\mathrm{Bu}$ & 4ab (76 [70:30]); 5b (7 [ndf]) \\
\hline 5 & $3 b$ & I & $\mathrm{Et}_{2} \mathrm{O}$ & $n-\mathrm{Bu}$ & 4bb (58 [98:2]) \\
\hline 6 & $3 a$ & $\mathrm{Br}$ & $\mathrm{CH}_{2} \mathrm{Cl}_{2}$ & Et & 4aa (39d $[78: 22]) ; 5 a\left(17^{d}[91: 9]\right)$ \\
\hline 7 & $3 a$ & $\mathrm{Br}$ & $\mathrm{CH}_{2} \mathrm{Cl}_{2}$ & $n-\mathrm{Bu}$ & 4ab (37 [76:24]); 5b (12 [nd $\left.]^{f}\right)$ \\
\hline
\end{tabular}

aReaction conditions : $\mathrm{R}_{2} \mathrm{Zn}$ (3 equiv), rt, $24 \mathrm{~h}$ under $\mathrm{Ar}$ atmosphere (see Experimental section).

${ }^{b}$ Combined yield of diastereomers after chromatography unless otherwise noted.

${ }^{c}$ Determined by ${ }^{1} \mathrm{H}$ NMR analysis of the crude material.

dThe reaction mixture was quenched with $\mathrm{D}_{2} \mathrm{O}$. The percentage of deuterium incorporation is given in parenthesis for each compound

e Determined by ${ }^{1} \mathrm{H}$ NMR spectroscopy based on analysis of the crude mixture with biphenyl as internal standard.

fNot determined.

unexpectedly, however, $40 \%$ of alkylidenetetrahydrofuran $\mathbf{5 a}$, wherein the bromine atom had been substituted by an ethyl group, was also isolated as a 79:21 Z/E mixture. Deuterium labeled 5a-D was produced following hydrolysis with $\mathrm{D}_{2} \mathrm{O}$ (Table 1, entry 2), thereby showing that an alkylidenezinc intermediate was being formed in the generation of this side-product under these reaction conditions.

When iodoalkyne $\mathbf{3 b}$ was used, a similar $40 \%$ yield of vinylic iodide $4 \mathbf{b a}$ was obtained, but this time exclusively as the $Z$ isomer (Table 1, entry 3). 5a was also produced, but in a lower $21 \%$ yield and similar diastereoselectivity ( $82: 18 \mathrm{Z} / \mathrm{E}$ ratio) Significantly lower levels of side-product formation arising from halogen substitution were observed when $n$ - $\mathrm{Bu}_{2} \mathrm{Zn}$ was used, thus leading to improved results (Table 1, entries 4 and 5). The reaction with bromoalkyne 3a provided vinylic bromide 4ab in $76 \%$ yield and 70:30 $Z / E$ ratio and only $7 \%$ of $\mathbf{5 b}$ Better, the reaction with iodoalkyne $\mathbf{3 b}$ afforded exclusively iodide $\mathbf{4 b b}$ in $58 \%$ yield and complete diastereoselectivity in favor of the $(Z)$ isomer. Formation of substitution side-products was also diminished when $\mathrm{CH}_{2} \mathrm{Cl}_{2}$ was used as the solvent instead of $\mathrm{Et}_{2} \mathrm{O}$, even though this had little impact on the efficiency and diastereoselectivity of vinyl halide formation (Table 1, entries 6 and 7). Reaction of $\mathrm{Et}_{2} \mathrm{Zn}$ with 3a provided vinyl bromide 4aa in 39\% yield (78:22 Z/E ratio) and 5a in 17\% yield, while reaction of $n-\mathrm{Bu}_{2} \mathrm{Zn}$ gave $4 \mathbf{a b}$ in $37 \%$ yield $(76: 24$ $Z / E$ ratio) and $\mathbf{5 b}$ in $12 \%$ yield. It is worthy of note that no difference was observed between the different dialkylzincs in this case.

The formation of alkylidenezinc derivatives 7 leading to compounds 5 is intriguing (Scheme 3). A first possible mechanistic route could involve the reaction of zinc carbenoid $\mathbf{6}$ and the

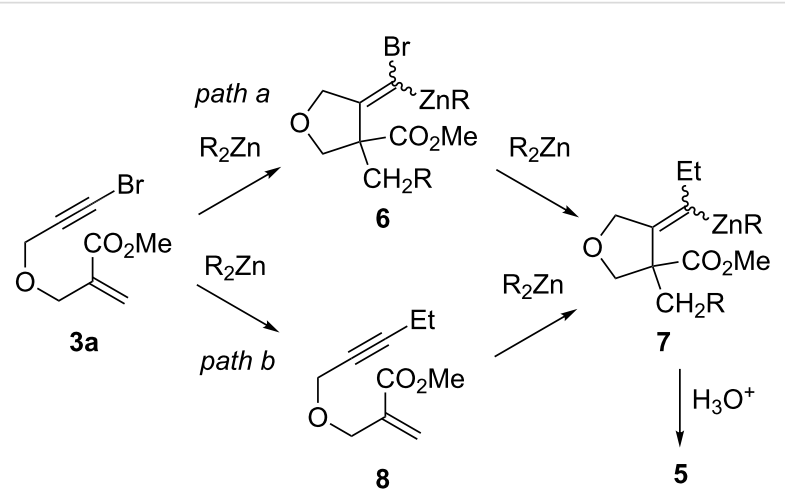

Scheme 3: Possible reaction pathways to account for the formation of product 5 . 
excess of dialkylzinc reagent via the intermediate formation of a zincate [48-51] (Scheme 3, path a). The stereoselectivity of such rearrangements is often dependent on the substrate structure, so the diastereopurity of $\mathbf{5}$ is not necessarily informative about that of 6 [48-51]. An alternative possibility to account for the formation of 7 could be the reaction of the dialkylzinc reagent with enoate $\mathbf{8}$ arising from a prior substitution of bromoalkyne 3a with the dialkylzinc reagent (Scheme 3, path b). Both the diastereoselectivity and the levels of deuterium incorporation are very close to those obtained for the reaction of diethylzinc with pure 8 [37], which argues in favor of this mechanistic scenario.

To try to discriminate between these possibilities we conducted some additional test experiments (Scheme 4). In agreement with the general consideration that dialkylzinc reagents do not undergo uncatalyzed cross-coupling reactions with bromoalkynes, no reaction was observed between $\mathrm{Et}_{2} \mathrm{Zn}$ and 1-bromohexyne (9) [54]. By contrast, bromoalkyne 11 having a silyloxy group at the propargylic position reacted smoothly to afford ethyl-substituted alkyne $\mathbf{1 0}$ along with alkene 12, which had incorporated two ethyl groups. 12 was isolated as a mixture of diastereoisomers in 70:30 dr. The fact that no reaction takes place between pure $\mathbf{1 0}$ and $\mathrm{Et}_{2} \mathrm{Zn}$ indicates that $\mathbf{1 2}$ is not formed by carbozincation. Hence, most likely it is formed by the reaction of $\mathrm{Et}_{2} \mathrm{Zn}$ and carbenoid $\mathbf{1 3}$ arising from the carbozincation of $\mathbf{1 1}$ (Scheme 4). Moreover, if $\mathbf{1 3}$ is indeed formed, it would also lead to alkyne 10 following Fritsch-Buttenberg-Wieschell (FBW) rearrangement [55-57]. Since the presence of the oxygen atom in the propargylic position should facilitate the carbometallation reaction [58], this mechanistic pathway provides a plausible explanation for the fact that bromine substitution occurs from $\alpha$-oxgenated bromoalkyne $\mathbf{1 1}$ and not from 9.

Regarding our 1,4 addition/carbocyclization sequence, these test experiments provide two important pieces of evidence for the behavior of 3a in the presence of a dialkylzinc. First, $\beta$-alkoxy bromoalkynes undergo direct substitution with $\mathrm{Et}_{2} \mathrm{Zn}$ to some extent. Second, alkylidenezinc carbenoids react with dialkylzincs to afford the bromine substitution product. Thus, formation of alkylidenezinc compound 7 (and thereby 5) most probably arises from both depicted mechanistic pathways (paths a and b, Scheme 3). In such a situation, we reasoned that in both possibilities, reducing the reaction time would limit the production of the unwanted side-products by limiting the contact time between the dialkylzinc reagent and either the starting bromoalkyne or the generated zinc carbenoid. Thus, we considered adding air to the reaction media in order to accelerate the oxidation of the dialkylzinc species and therefore radical production (Table 2 ).

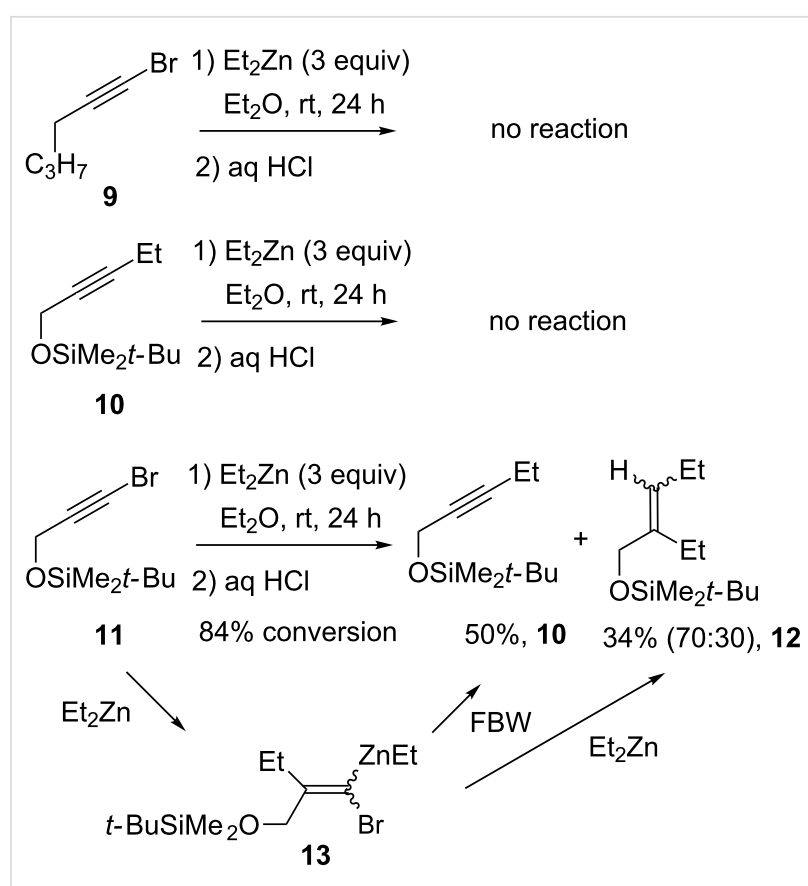

Scheme 4: Test experiments to gain insight into the mechanism of formation of alkylidene zinc intermediate 7 .

A reduced amount of side-product 5 was indeed observed in the reaction of enoate 3a with $\mathrm{Et}_{2} \mathrm{Zn}$ in $\mathrm{CH}_{2} \mathrm{Cl}_{2}$ at room temperature in the presence of added dry air (Table 2, entry 1). A mixture of vinyl bromide 4aa and alkene 5a in a 84:16 ratio and in $69 \%$ overall yield was obtained. However the diastereoselectivity of the formation of 4aa dropped significantly. Lowering the reaction temperature had a highly beneficial impact on the reaction outcome. At $0{ }^{\circ} \mathrm{C}$, the formation of 5a was totally suppressed, and 4aa was obtained with a much better diastereoselectivity, though remarkably in favor of the $E$ isomer (Table 2, entry 2). At $-30{ }^{\circ} \mathrm{C}$, the exclusive and totally diastereoselective formation of $(E)-\mathbf{4 a a}$ in excellent $89 \%$ isolated yield was obtained (Table 2, entry 3 ). Hydrolysis with $\mathrm{D}_{2} \mathrm{O}$ led to $(E)$-4aa-D with $83 \%$ deuterium incorporation when either $\mathrm{CH}_{2} \mathrm{Cl}_{2}$ or DCE were used as solvent (entries 4 and 5), therefore evidencing the intermediate stereoselective formation of an alkylidene zinc carbenoid. Similar results were obtained by using $n-\mathrm{Bu}_{2} \mathrm{Zn}$, indicating that the process is quite general (Table 2, entry 6).

The diastereoselectivity of the formation of $4 \mathbf{a a}$ seemed to be dependent not only on the reaction temperature, but also on the total reaction time (compare Table 1, entry 6 and Table 2, entry 1). Suspecting a possible $Z / E$ isomerization of the alkylidenezinc carbenoid intermediate, we conducted an experiment wherein air was added to a mixture of enoate $\mathbf{3 a}$ and $\mathrm{Et}_{2} \mathrm{Zn}$ in $\mathrm{CH}_{2} \mathrm{Cl}_{2}$ at $-30{ }^{\circ} \mathrm{C}$, and the reaction was first kept for $1 \mathrm{~h}$ at this temperature and then for $23 \mathrm{~h}$ at room temperature (Table 2, 
Table 2: 1,4-Addition/carbozincation of dialkylzincs on $\mathbf{3 a}$ in the presence of added air. ${ }^{\text {a }}$

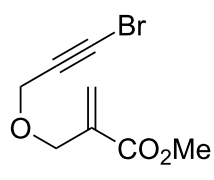

$3 a$

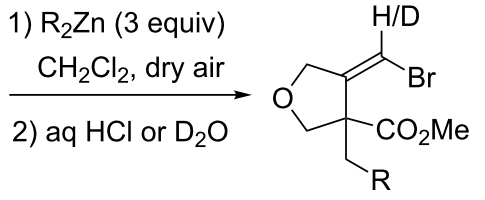

$(E)-4$<smiles>[R]CC1(C(=O)O)COCC1=C[OH2+]</smiles>

(Z)-5

\begin{tabular}{|c|c|c|c|c|c|}
\hline Entry & $\mathrm{R}$ & Reaction conditions & Products [ratio] & Yield ${ }^{b}(\%)$ & $\mathrm{dr}^{\mathrm{C}}$ of product $4(E / Z)$ \\
\hline 1 & Et & $\mathrm{rt}, 1 \mathrm{~h}$ & 4aa/(Z)-5a [84:16] & $69^{d}$ & $54: 46$ \\
\hline 2 & Et & $0^{\circ} \mathrm{C}, 1 \mathrm{~h}$ & $4 a a$ & 93 & $87: 13$ \\
\hline 3 & Et & $-30^{\circ} \mathrm{C}, 1 \mathrm{~h}$ & 4aa & 89 & $>98: 2$ \\
\hline 4 & Et & $-30^{\circ} \mathrm{C}, 1 \mathrm{~h}$ & $4 a a-D^{e}$ & $95^{d}$ & $>98(83 \%$ D $): 2$ \\
\hline 5 & Et & $-30^{\circ} \mathrm{C}, 1 \mathrm{~h}, \mathrm{DCE}^{\mathrm{f}}$ & 4aa-De & 89 & $>98(83 \%$ D $): 2$ \\
\hline 6 & $\mathrm{Bu}$ & $-30^{\circ} \mathrm{C}, 1 \mathrm{~h}$ & $4 a b$ & 93 & $>98: 2$ \\
\hline 7 & Et & $-30{ }^{\circ} \mathrm{C}, 1 \mathrm{~h}$ then $\mathrm{rt}, 24 \mathrm{~h}$ & 4aa/(Z)-5a [78:22] & $78^{d}$ & $44: 56$ \\
\hline 8 & Et & $-30{ }^{\circ} \mathrm{C}, 1 \mathrm{~h}$ then $\mathrm{rt}, 24 \mathrm{~h}$ & 4aa-De ${ }^{e} /(Z)-5 a-D^{g}[78: 22]$ & $78^{d}$ & $44(<10 \% \mathrm{D}): 56(<10 \% \mathrm{D})$ \\
\hline
\end{tabular}

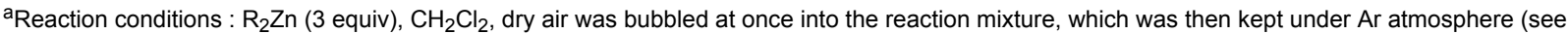
Experimental section).

${ }^{b}$ Combined yield of products after chromatography unless otherwise noted.

CDetermined by ${ }^{1} \mathrm{H}$ NMR analysis of the crude material.

${ }^{\mathrm{d} D e t e r m i n e d ~ b y ~}{ }^{1} \mathrm{H}$ NMR spectroscopy based on analysis of the crude mixture with biphenyl as the internal standard.

eThe reaction mixture was quenched with $\mathrm{D}_{2} \mathrm{O}$. The percentage of deuterium incorporation is given in parenthesis for each isomer.

fDCE = 1,2-dichloroethane was used as solvent instead of $\mathrm{CH}_{2} \mathrm{Cl}_{2}$.

$\mathrm{g}_{30} \%$ deuterium incorporation was observed for product $\mathbf{5 a - D}$.

entry 7). Following acidic quench, very similar results to those noted for the same reaction carried out at room temperature (Table 2, entry 1) were observed. 4aa was recovered in $61 \%$ yield as a $56: 44$ mixture of isomers along with alkene $(Z)-5 \mathbf{a}$ in $22 \%$ yield. It is worthy to note that very low levels of deuterium incorporation were observed in this case.

These results have a three-fold consequence. First, they indicate that $Z / E$ isomerization of the alkylidenezinc carbenoid occurs between $-30{ }^{\circ} \mathrm{C}$ and room temperature. Second, it demonstrates that alkene $\mathbf{5 a}$ can be formed by the reaction between the zinc carbenoid and $\mathrm{Et}_{2} \mathrm{Zn}$ (Scheme 3, path a), and that in such a case the transformation is stereoselective. Third, when oxygen is introduced into the reaction media, the alkylidenezinc carbenoid is eventually demetallated upon standing at room temperature.

The different results obtained for the 1,4-addition/carbozincation of enoates having pendant bromoalkynes are consistent with our anticipated zinc atom radical transfer mechanism (Scheme 1) and can be rationalized according to the following scenario (Scheme 5). The process involves the initial 1,4-addition of radical $\mathrm{R}$ to the starting enoate and the subsequent 5-exo-dig cyclisation of enoxy radical 14 to provide a-bromovinyl radical 15 of $E$ geometry. Substitution by electron-withdrawing groups slows down $E$ to $Z$ isomerization of vinylic radicals, and therefore, due to the presence of the bromine atom, interconversion of $(E)-\mathbf{1 5}$ into $(Z)-\mathbf{1 5}$ should not be fast. Thus, $(E)-\mathbf{1 5}$ reacts by $\mathrm{Zn}$ atom transfer prior to its equilibration to provide stereoselectively carbenoid (Z)-6 [59] and to some extent by $\mathrm{H}$-atom transfer to give reduced bromoalkene (E)-4 [60]. Upon warming, (Z)-6 isomerizes to its more stable isomer $(E)-6$ wherein the zinc atom is coordinated intramolecularly to the adjacent ester. To a minor extent, reaction with the excess dialkylzinc present in the reaction media provides alkylidenezinc $(E)-7$ stereoselectively. Note, however, that in the case where reactions are conducted at room temperature, $E / Z$ equilibration of the intermediate radical 15 should be faster and zinc atom transfer from (Z)-15 may also contribute to the formation of $(E)-\mathbf{6}$.

Two situations are next to be distinguished. Under the conditions involving excess air, carbenoid $\mathbf{6}$ is protonated in the reaction media (even though we have not identified the proton source). It is possible that protonation occurs prior to full $E$ to $Z$ isomerization and vinyl bromide $\mathbf{4}$ is obtained in low diastereoselectivity. Under the conditions involving only a trace of air, after $24 \mathrm{~h}$ at room temperature, carbenoid $\mathbf{6}$ is still present and 


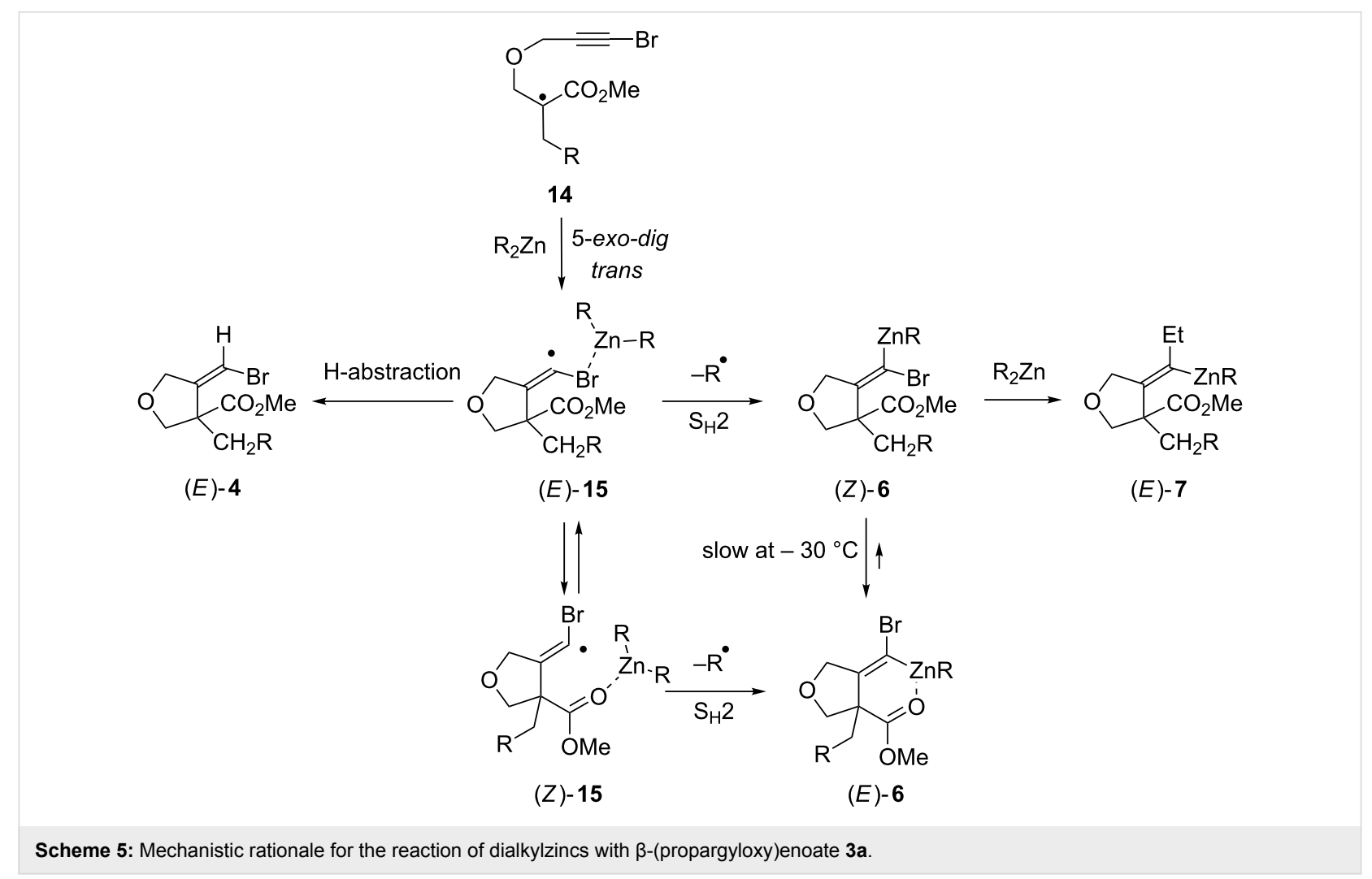

total $Z$ to $E$ isomerization has occurred. The reason why vinyl bromide 4 is only isolated with moderate diastereoselectivity following hydrolysis, is that $(E)-\mathbf{4}$, formed from $(E)-\mathbf{1 5}$ by $\mathrm{H}$-abstraction, is present from the start.

We finally considered the prospect to carry out the carbozincation of bromoalkynes using a combination of an alkyl iodide and dimethylzinc (Table 3). Towards this end, we first treated enoate 3a with $\mathrm{Me}_{2} \mathrm{Zn}$, following our previously reported optimized conditions for the 1,4-addition/carbozincation of $\beta$-(propargyloxy)enoates with $\mathrm{Me}_{2} \mathrm{Zn}$ [38], which proceeds in $\mathrm{CH}_{2} \mathrm{Cl}_{2}$ at $0{ }^{\circ} \mathrm{C}$ and under continuous introduction of dry air over a period of $1 \mathrm{~h}$ (Table 3, entry 1 ). After acidic quench, vinylic bromide $(E)-\mathbf{4 a c}[61]$ was isolated in $77 \%$ yield as a single diastereoisomer. The stereoselective formation of an alkylidenezinc carbenoid intermediate was this time evidenced by treating the reaction mixture with iodine (Table 3, entry 2 ). Vinylic dihalide 16 was isolated in $64 \%$ yield, again as a single $Z$ diastereoisomer. Thus, $\mathrm{Me}_{2} \mathrm{Zn}$ showed a similar reactivity to its higher homologues $\mathrm{Et}_{2} \mathrm{Zn}$ and $n-\mathrm{Bu}_{2} \mathrm{Zn}$, with the additional advantage that no direct formation of vinyl bromide $(E)-\mathbf{4 a c}$ by hydrogen abstraction was observed.

In the presence of 5 equiv iPrI, a mixture of two (diastereomerically pure) compounds $\mathbf{4 a d}$ and $\mathbf{4 a c}$ in 87:13 ratio was observed. Incorporation of the iPr moiety was therefore the major reaction pathway. The competitive addition of a $\mathrm{Me}$ group could be reduced by increasing the amount of iPrI to 10 equiv (Table 3, entries 3 and 4). However, in this case, significant amounts of vinylic dihalide 17 were also isolated. Thus, if large amounts of iodide are used, radical iodine atom transfer between iPrI and the $\alpha$-bromovinylic radical 15 resulting from the cyclization step (Scheme 5) becomes competitive with the desired zinc atom transfer and hampers the carbozincation process.

\section{Conclusion}

In conclusion, we have shown that $\beta$-(propargyloxy)enoates having pendant iodo- and bromoalkynes undergo a 1,4-addition/ carbozincation sequence by reaction with dialkylzincs or with alkyliodides in the presence of dimethylzinc. The sequence involves a radical chain mechanism initiated by air and provides the proof of concept that alkylidenezinc carbenoids can be prepared by carbozincation based on zinc atom transfer. In the disclosed process, we have demonstrated that the formation of a bromocarbenoid intermediate is fully stereoselective at $-30{ }^{\circ} \mathrm{C}$ and arises from a formal anti-selective carbozincation reaction. Upon warming, the zinc carbenoid is stereochemically labile and isomerizes to its more stable form. In the absence of added air, no decomposition of the carbenoid intermediate is observed at room temperature for at least $24 \mathrm{~h}$. Deuterium labeling and iodolysis experiments evidence that the zinc carbenoids 
Table 3: $\mathrm{Me}_{2} \mathrm{Zn}$-mediated 1,4-addition/carbozincation of alkyl iodides with 3a in the presence of added air. ${ }^{\mathrm{a}}$<smiles>COC(=O)COCC#CBr</smiles>

3a
1) $\mathrm{Me}_{2} \mathrm{Zn}$ (5 equiv), dry air,

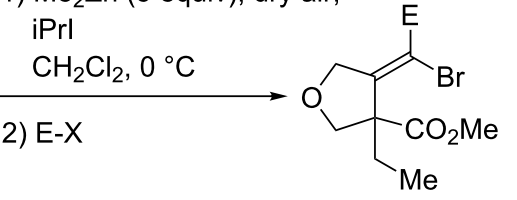

$+$<smiles>COC(=O)C1(CC(C)C)COC/C1=C(/F)Br</smiles>

$$
\begin{array}{ll}
\text { 4ac }(E=H) & \text { 4ad }(E=H) \\
\text { 4ac-D }(E=D) & \text { 4ad-D }(E=D) \\
16(E=I) & 17(E=I)
\end{array}
$$

\begin{tabular}{|c|c|c|c|c|}
\hline Entry & iPrl (equiv) & $\mathrm{E}-\mathrm{X}$ & Yield $^{\mathrm{b}}(\%)$ & Products [ratio] \\
\hline 1 & 0 & $\mathrm{H}_{2} \mathrm{O}$ & 77 & $4 \mathrm{ac}^{\mathrm{c}}$ \\
\hline 2 & 0 & $\mathrm{I}_{2}$ & 64 & 16 \\
\hline $3^{d}$ & 5 & $\mathrm{H}_{2} \mathrm{O}$ & 59 & 4ad/4ac $[87: 13]$ \\
\hline $4^{d}$ & 10 & $\mathrm{H}_{2} \mathrm{O}$ & 87 & 4ad/4ac/17 [75:6:19] \\
\hline $5^{d}$ & 10 & $\mathrm{D}_{2} \mathrm{O}$ & 75 & 4ad-D/4ac-D/17 [75 (95\% D):6 (95\% D):19] \\
\hline
\end{tabular}

aReaction conditions: $\mathrm{Me}_{2} \mathrm{Zn}$ (5 equiv), $\mathrm{Prl}$ (equiv), $\mathrm{CH}_{2} \mathrm{Cl}_{2}, 0^{\circ} \mathrm{C}, 20 \mathrm{~mL}$ dry air was bubbled during $1 \mathrm{~h}$ into the reaction mixture via a syringe pump. bCombined yield of isolated products after chromatography unless otherwise noted.

'The product was contaminated with $\sim 10 \%$ of product resulting from the addition of the dichloromethyl radical $(4 \mathrm{ae}, \mathrm{R}=\mathrm{CHCl})$.

$\mathrm{d}_{3}$ equiv $\mathrm{Me}_{2} \mathrm{Zn}$ were used.

prepared under such reactions can act as typical nucleophiles and should, thus, be well-suited for subsequent functionalization [47-51]. Furthermore, as indicated with the formation of some side-products observed during this work, they should also react readily as electrophiles toward organometallic nucleophiles and undergo intramolecular nucleophilic substitution reactions [47-51].

\section{Experimental}

Experiments involving organometallic compounds were carried out in dried glassware under a positive pressure of dry Ar. All solvents were distilled to remove stabilizers and dried with a MBRAUN Solvent Purification System SPS-800. $n-\mathrm{Bu}_{2} \mathrm{Zn}$ (Fluka, $\sim 1 \mathrm{~N}$ in heptane), $\mathrm{Et}_{2} \mathrm{Zn}$ (Aldrich, 1.0 $\mathrm{M}$ in hexanes), $\mathrm{Me}_{2} \mathrm{Zn}$ (Aldrich, 1.0 $\mathrm{M}$ in heptane) and all other reagents were of commercial quality and were used without purification. ${ }^{1} \mathrm{H}$ NMR, ${ }^{13} \mathrm{C}$ NMR spectra were recorded with a Bruker AVANCE 400 spectrometer fitted with BBFO probe with Z gradient. Chemical shifts are reported in $\delta$ relative to an internal standard of residual chloroform $\left(\delta 7.27\right.$ for ${ }^{1} \mathrm{H}$ NMR and 77.16 for ${ }^{13} \mathrm{C}$ NMR). IR spectra were recorded with an ATR diamond spectrophotometer. High-resolution mass spectra (HRMS) were obtained on a Finnigan MAT 95.

General Procedure 1. Reaction of $\boldsymbol{n}-\mathrm{Bu}_{2} \mathrm{Zn}$ and $\mathrm{Et}_{2} \mathrm{Zn}$ with $\beta$-(propargyloxy)enoates $3 a$ and $3 b$ having pendant haloalkynes in the presence of a trace amount of air (Table 1): Under argon, to a stirred solution of $\beta$-(propargyl- oxy)enoate $(0.2 \mathrm{mmol})$ in $\mathrm{Et}_{2} \mathrm{O}(1 \mathrm{~mL})$ at room temperature was added $\mathrm{R}_{2} \mathrm{Zn}(0.6 \mathrm{mmol})$. The reaction mixture was stirred at room temperature for $24 \mathrm{~h}$. The reaction was hydrolyzed with an aqueous solution of $\mathrm{HCl}(1 \mathrm{M}, 10 \mathrm{~mL})$. The layers were separated, the aqueous one being extracted with $\mathrm{Et}_{2} \mathrm{O}(2 \times 15 \mathrm{~mL})$. The combined organic layers were washed with brine, dried over $\mathrm{MgSO}_{4}$, and concentrated under reduced pressure, and the residue was purified by flash chromatography (pentane/ether).

General Procedure 2. Reaction of $\boldsymbol{n}-\mathrm{Bu}_{2} \mathrm{Zn}$ and $\mathrm{Et}_{2} \mathrm{Zn}$ with $\beta$-(propargyloxy)enoate $3 \mathrm{a}$ in the presence of added air (Table 2): Under argon, to a stirred solution of $\beta$-(propargyloxy)enoate 3a $(0.2 \mathrm{mmol})$ in $\mathrm{CH}_{2} \mathrm{Cl}_{2}(2 \mathrm{~mL})$ at $-30{ }^{\circ} \mathrm{C}$ was added $\mathrm{R}_{2} \mathrm{Zn}(0.6 \mathrm{mmol})$. Air $(2 \mathrm{~mL})$ was bubbled at once into the solution via a syringe fitted with a $\mathrm{CaCl}_{2}$ guard and the reaction mixture was stirred at $-30{ }^{\circ} \mathrm{C}$ for $1 \mathrm{~h} . \mathrm{CH}_{2} \mathrm{Cl}_{2}(20 \mathrm{~mL})$ and an aqueous solution of $\mathrm{HCl}(1 \mathrm{M}, 10 \mathrm{~mL})$ were added to quench the reaction. The layers were separated, the aqueous one being extracted with $\mathrm{Et}_{2} \mathrm{O}(2 \times 15 \mathrm{~mL})$. The combined organic layers were washed with brine, dried over $\mathrm{MgSO}_{4}$, and concentrated under reduced pressure to afford the crude product.

(Z)-Methyl 4-(bromomethylene)-3-propyltetrahydrofuran3-carboxylate $((Z)-4 a a)$ : Prepared according to general procedure 1 from enoate $3 \mathbf{a}(50 \mathrm{mg}, 0.2 \mathrm{mmol})$ and $\mathrm{Et}_{2} \mathrm{Zn}(0.6 \mathrm{~mL}$, $1.0 \mathrm{M}$ in hexanes, $0.6 \mathrm{mmol})$. Purification by flash chromatography with pentane/ether (95:05) as eluent gave the title compound ((Z)-4aa) $(19 \mathrm{mg}, 33 \%)$ as a colorless oil. IR (neat): 
2958, 1730, 1434, 1219, 1072, 938, $722 \mathrm{~cm}^{-1} ;{ }^{1} \mathrm{H}$ NMR $\left(400 \mathrm{MHz}, \mathrm{CDCl}_{3}\right) \delta 6.34(\mathrm{t}, J=2.7 \mathrm{~Hz}, 1 \mathrm{H}), 4.42(\mathrm{~d}(\mathrm{AB}$ system), $J=9.1 \mathrm{~Hz}, 1 \mathrm{H}), 4.40(\mathrm{~d} \mathrm{br}, J=2.9 \mathrm{~Hz}, 2 \mathrm{H}), 3.84$ (d(AB system), $J=9.1 \mathrm{~Hz}, 1 \mathrm{H}), 3.74(\mathrm{~s}, 3 \mathrm{H}), 1.90(\mathrm{~m}, 1 \mathrm{H})$, $1.68(\mathrm{~m}, 1 \mathrm{H}), 1.24(\mathrm{~m}, 2 \mathrm{H}), 0.91(\mathrm{t}, J=7.3 \mathrm{~Hz}, 3 \mathrm{H}) ;{ }^{13} \mathrm{C} \mathrm{NMR}$ $\left(100 \mathrm{MHz}, \mathrm{CDCl}_{3}\right) \delta 172.3,146.6,100.4,75.7,72.8,58.5,52.6$, $39.5,18.8,14.2$; HRMS-ESI $(\mathrm{m} / \mathrm{z}):[\mathrm{M}+\mathrm{Na}]^{+}$calcd for $\mathrm{C}_{10} \mathrm{H}_{15} \mathrm{O}_{3} \mathrm{BrNa}$ : 285.00968; found: 285.00990 .

(E)-Methyl 4-(bromomethylene)-3-propyltetrahydrofuran3-carboxylate $((\boldsymbol{E})$-4aa): Prepared according to general procedure 2 from enoate $3 \mathrm{a}(47 \mathrm{mg}, 0.2 \mathrm{mmol})$ and $\mathrm{Et}_{2} \mathrm{Zn}(0.6 \mathrm{~mL}$, $1.0 \mathrm{M}$ in hexanes, $0.6 \mathrm{mmol})$. The title compound ((E)-4aa) was isolated pure ( $47 \mathrm{mg}, 89 \%$ ) as a colorless oil and did not require further purification. IR (neat): 2960, 2873, 1769, 1730, 1433, 1217, 1122, 1074, 968, 938, $742 \mathrm{~cm}^{-1} ;{ }^{1} \mathrm{H}$ NMR $(400 \mathrm{MHz}$, $\left.\mathrm{CDCl}_{3}\right) \delta 6.15(\mathrm{t}, J=1.9 \mathrm{~Hz}, 1 \mathrm{H}), 4.39(\mathrm{dd}(\mathrm{ABX}$ system $), J=$ $12.7,1.9 \mathrm{~Hz}, 1 \mathrm{H}), 4.32$ (dd(ABX system), $J=12.7,1.8 \mathrm{~Hz}$, $1 \mathrm{H}), 4.12(\mathrm{~d}(\mathrm{AB}$ system $), J=8.9 \mathrm{~Hz}, 1 \mathrm{H}), 3.97$ (d(AB system), $J=8.9 \mathrm{~Hz}, 1 \mathrm{H}), 3.74(\mathrm{~s}, 3 \mathrm{H}), 2.13(\mathrm{td}, J=13.5,4.6 \mathrm{~Hz}, 1 \mathrm{H})$, $1.90(\mathrm{dt}, J=12.5,4.4 \mathrm{~Hz}, 1 \mathrm{H}), 1.50-1.30(\mathrm{~m}, 1 \mathrm{H}), 1.30-1.25$ $(\mathrm{m}, 1 \mathrm{H}), 0.95(\mathrm{t}, J=7.3 \mathrm{~Hz}, 3 \mathrm{H}) ;{ }^{13} \mathrm{C} \mathrm{NMR}\left(100 \mathrm{MHz}, \mathrm{CDCl}_{3}\right)$ $\delta$ 173.3, 146.7, 98.5, 78.3, 73.8, 58.3, 52.7, 34.7, 17.9, 14.8; HRMS-ESI $(\mathrm{m} / \mathrm{z}):[\mathrm{M}+\mathrm{Na}]^{+}$calcd for $\mathrm{C}_{10} \mathrm{H}_{15} \mathrm{O}_{3} \mathrm{BrNa}$ : 285.0097; found: 285.0091 .

(Z)-Methyl 4-(iodomethylene)-3-pentyltetrahydrofuran-3carboxylate $((Z)-4 b b)$ : Prepared according to general procedure 1 from enoate $3 \mathbf{b}(40 \mathrm{mg}, 0.14 \mathrm{mmol})$ and $\mathrm{Bu}_{2} \mathrm{Zn}$ $(0.42 \mathrm{~mL}, \sim 1 \mathrm{~N}$ in heptane, $0.42 \mathrm{mmol})$. Purification by flash chromatography with pentane/ether (80:20) as eluent gave the title compound $((Z)-\mathbf{4 b b})(28 \mathrm{mg}, 58 \%)$ as a colorless oil. IR (neat): 2951, 2925, 2856, 1731, 1434, 1230, 1073, 939, $730 \mathrm{~cm}^{-1} .{ }^{1} \mathrm{H}$ NMR $\left(400 \mathrm{MHz}, \mathrm{CDCl}_{3}\right) \delta 6.36(\mathrm{t}, J=2.6 \mathrm{~Hz}$, $1 \mathrm{H}), 4.49(\mathrm{~d}(\mathrm{AB}$ system $), J=9.1 \mathrm{~Hz}, 1 \mathrm{H}), 4.31(\mathrm{~d} \mathrm{br}$, $J=2.6 \mathrm{~Hz}, 2 \mathrm{H}), 3.90(\mathrm{~d}(\mathrm{AB}$ system $), J=9.1 \mathrm{~Hz}, 1 \mathrm{H}), 3.74$ (s, $3 \mathrm{H}), 1.90(\mathrm{~m}, 1 \mathrm{H}), 1.66(\mathrm{~m}, 1 \mathrm{H}), 1.40-1.20(\mathrm{~m}, 6 \mathrm{H}), 0.91(\mathrm{t}, J=$ $6.9 \mathrm{~Hz}, 3 \mathrm{H}) ;{ }^{13} \mathrm{C} \mathrm{NMR}\left(100 \mathrm{MHz}, \mathrm{CDCl}_{3}\right) \delta 172.3,152.4,76.5$, $76.2,71.3,59.7,52.7,37.3,32.0,25.1,22.5,14.1$.

(E)-Methyl 4-(bromomethylene)-3-pentyltetrahydrofuran-3carboxylate $((E)-4 a b)$ : Prepared according to general procedure 2 from enoate 3a $(47 \mathrm{mg}, 0.2 \mathrm{mmol})$ and $\mathrm{Bu}_{2} \mathrm{Zn}(0.6 \mathrm{~mL}$, $\sim 1 \mathrm{~N}$ in heptane, $0.6 \mathrm{mmol})$. The title compound ((E)-4ab) was isolated pure (55 mg, 93\%) as a colorless oil and did not require further purification. IR (neat): 2955, 2927, 2856, 1771, 1733, $1433,1260,1230,1217,1122,1074,936,910,731 \mathrm{~cm}^{-1}$; ${ }^{1} \mathrm{H}$ NMR $\left(400 \mathrm{MHz}, \mathrm{CDCl}_{3}\right) \delta 6.15(\mathrm{t}, J=1.9 \mathrm{~Hz}, 1 \mathrm{H}), 4.39$ $(\operatorname{dd}(\mathrm{ABX}$ system $), J=12.7,2.0 \mathrm{~Hz}, 1 \mathrm{H}), 4.32(\mathrm{dd}(\mathrm{ABX}$ system), $J=12.7,1.8 \mathrm{~Hz}, 1 \mathrm{H}), 4.12(\mathrm{~d}(\mathrm{AB}$ system $), J=8.9 \mathrm{~Hz}$, $1 \mathrm{H}), 3.97(\mathrm{~d}(\mathrm{AB}$ system $), J=8.9 \mathrm{~Hz}, 1 \mathrm{H}), 3.74(\mathrm{~s}, 3 \mathrm{H}), 2.15$ $(\mathrm{td}, J=13.7,4.2 \mathrm{~Hz}, 1 \mathrm{H}), 1.91(\mathrm{dt}, J=12.2,4.4 \mathrm{~Hz}, 1 \mathrm{H})$, $1.50-1.20(\mathrm{~m}, 6 \mathrm{H}), 0.88(\mathrm{t}, J=7.0 \mathrm{~Hz}, 3 \mathrm{H}) ;{ }^{13} \mathrm{C} \mathrm{NMR}$ $\left(100 \mathrm{MHz}, \mathrm{CDCl}_{3}\right) \delta 173.3,146.7,98.6,78.3,73.9,58.2,52.7$, 32.5, 32.4, 24.1, 22.7, 14.3; HRMS-ESI $(\mathrm{m} / \mathrm{z})$ : $[\mathrm{M}+\mathrm{Na}]^{+}$calcd for $\mathrm{C}_{12} \mathrm{H}_{19} \mathrm{O}_{3} \mathrm{BrNa}$ : 313.0410; found: 313.0413 .

(E)-Methyl 4-(bromomethylene)-3-ethyltetrahydrofuran-3carboxylate $((\boldsymbol{E})-\mathbf{4 a c})$ (Table 3 , entry 1$)$ : Under argon, to a stirred solution of $\beta$-(propargyloxy)enoate 3a (46 mg, $0.2 \mathrm{mmol})$ in $\mathrm{CH}_{2} \mathrm{Cl}_{2}(1 \mathrm{~mL})$ at $0{ }^{\circ} \mathrm{C}$ was added $\mathrm{Me}_{2} \mathrm{Zn}(1 \mathrm{~mL}$, $1.0 \mathrm{M}$ in heptane, $1.0 \mathrm{mmol})$. Air $(20 \mathrm{~mL})$ was slowly introduced over $1 \mathrm{~h}$ into the solution via a syringe pump by using a syringe fitted with a $\mathrm{CaCl}_{2}$ guard. The reaction mixture was then stirred at $0{ }^{\circ} \mathrm{C}$ for $1 \mathrm{~h} . \mathrm{CH}_{2} \mathrm{Cl}_{2}(5 \mathrm{~mL})$ was then added, and the reaction was hydrolyzed with an aqueous solution of $\mathrm{HCl}$ ( $1 \mathrm{M}, 5 \mathrm{~mL}$ ). The layers were separated, the aqueous one being extracted with $\mathrm{CH}_{2} \mathrm{Cl}_{2}(3 \times 10 \mathrm{~mL})$. The combined organic layers were washed with brine, dried over $\mathrm{MgSO}_{4}$ and concentrated under reduced pressure. Purification by flash chromatography on silica gel (pentane/ether 80:20) afforded the title compound ((E)-4ac) $(38 \mathrm{mg}, 77 \%)$ as a colorless oil. IR (neat): 2953, 1767, 1731, 1638, 1229, 1138, 1034, 936, $786 \mathrm{~cm}^{-1}$; ${ }^{1} \mathrm{H}$ NMR $\left(400 \mathrm{MHz}, \mathrm{CDCl}_{3}\right) \delta 6.17(\mathrm{t}, J=1.9 \mathrm{~Hz}, 1 \mathrm{H}), 4.41$ $(\mathrm{dd}(\mathrm{ABX}$ system $), J=12.7,1.9 \mathrm{~Hz}, 1 \mathrm{H}), 4.33(\mathrm{dd}(\mathrm{ABX}$ system), $J=12.7,1.9 \mathrm{~Hz}, 1 \mathrm{H}), 4.13(\mathrm{~d}(\mathrm{AB}$ system),$J=8.9 \mathrm{~Hz}$, $1 \mathrm{H}), 3.98(\mathrm{~d}(\mathrm{AB}$ system $), J=8.9 \mathrm{~Hz}, 1 \mathrm{H}), 3.75(\mathrm{~s}, 3 \mathrm{H}), 2.21$ $(\mathrm{m}, 1 \mathrm{H}), 2.00(\mathrm{~m}, 1 \mathrm{H}), 0.96(\mathrm{t}, J=7.5 \mathrm{~Hz}, 3 \mathrm{H}) ;{ }^{13} \mathrm{C} \mathrm{NMR}$ $\left(100 \mathrm{MHz}, \mathrm{CDCl}_{3}\right) \delta 173.2,146.4,98.5,77.9,73.8,58.5,52.6$, $25.2,8.9$; HRMS-ESI $(\mathrm{m} / \mathrm{z}):[\mathrm{M}+\mathrm{Na}]^{+}$calcd for $\mathrm{C}_{9} \mathrm{H}_{13} \mathrm{O}_{3} \mathrm{BrNa}$ : 270.99403; found: 270.99477 .

(E)-Methyl 4-(bromomethylene)-3-isobutyltetrahydrofuran3-carboxylate ((E)-4ad) (Table 3, entry 4): Under argon, to a stirred solution of $\beta$-(propargyloxy)enoate 3a (47 mg, $0.2 \mathrm{mmol})$ and $\operatorname{PrI}(0.2 \mathrm{~mL}, 2.0 \mathrm{mmol})$ in $\mathrm{CH}_{2} \mathrm{Cl}_{2}(1 \mathrm{~mL})$ at $0{ }^{\circ} \mathrm{C}$ was added $\mathrm{Me}_{2} \mathrm{Zn}(0.6 \mathrm{~mL}, 1.0 \mathrm{M}$ in heptane, $0.6 \mathrm{mmol})$. Air $(20 \mathrm{~mL})$ was slowly introduced over $1 \mathrm{~h}$ into the solution via a syringe pump by using a syringe fitted with a $\mathrm{CaCl}_{2}$ guard. The reaction mixture was then stirred at $0{ }^{\circ} \mathrm{C}$ for $1 \mathrm{~h} . \mathrm{CH}_{2} \mathrm{Cl}_{2}$ $(5 \mathrm{~mL})$ was then added and the reaction was hydrolyzed with an aqueous solution of $\mathrm{HCl}(1 \mathrm{M}, 5 \mathrm{~mL})$. The layers were separated, the aqueous one being extracted with $\mathrm{CH}_{2} \mathrm{Cl}_{2}(3 \times$ $10 \mathrm{~mL}$ ). The combined organic layers were washed with brine, dried over $\mathrm{MgSO}_{4}$ and concentrated under reduced pressure. Purification by flash chromatography on silica gel (pentane/ ether 50:50) afforded the title compound ((E)-4ad) (36 mg, $65 \%$ ) as a colorless oil. IR (neat): 2953, 2870, 1732, 1640, 1230, 1126, 1073, 937, $695 \mathrm{~cm}^{-1} ;{ }^{1} \mathrm{H}$ NMR (400 MHz, $\left.\mathrm{CDCl}_{3}\right)$ $\delta 6.15(\mathrm{t}, J=1.9 \mathrm{~Hz}, 1 \mathrm{H}), 4.40(\mathrm{~d}, J=1.9 \mathrm{~Hz}, 2 \mathrm{H}), 4.15(\mathrm{~d}(\mathrm{AB}$ system $), J=8.9 \mathrm{~Hz}, 1 \mathrm{H}), 4.02(\mathrm{~d}(\mathrm{AB}$ system $), J=8.9 \mathrm{~Hz}, 1 \mathrm{H})$, $3.74(\mathrm{~s}, 3 \mathrm{H}), 2.05(\mathrm{~m}, 2 \mathrm{H}), 1.77(\mathrm{~m}, 1 \mathrm{H}), 0.96(\mathrm{~d}, J=8.4 \mathrm{~Hz}$, 
$3 \mathrm{H}), 0.95(\mathrm{~d}, J=8.4 \mathrm{~Hz}, 3 \mathrm{H}) ;{ }^{13} \mathrm{C} \mathrm{NMR}\left(100 \mathrm{MHz}, \mathrm{CDCl}_{3}\right) \delta$ 173.1, 146.9, 98.6, 78.0, 73.6, 58.1, 52.5, 40.5, 24.9, 24.5, 24.4 HRMS-ESI $(\mathrm{m} / \mathrm{z}):[\mathrm{M}+\mathrm{Na}]^{+}$calcd for $\mathrm{C}_{11} \mathrm{H}_{17} \mathrm{O}_{3} \mathrm{BrNa}$ : 299.02533; found: 299.02606 .

(Z)-Methyl 4-(bromoiodomethylene)-3-ethyltetrahydrofuran-3-carboxylate (16) (Table 3, entry 2): Under argon, to a stirred solution of $\beta$-(propargyloxy)enoate 3a (45 mg, $0.2 \mathrm{mmol})$ in $\mathrm{CH}_{2} \mathrm{Cl}_{2}(1 \mathrm{~mL})$ at $0{ }^{\circ} \mathrm{C}$ was added $\mathrm{Me}_{2} \mathrm{Zn}(1 \mathrm{~mL}$, 1.0 $\mathrm{M}$ in heptane, $1.0 \mathrm{mmol})$. Air $(20 \mathrm{~mL})$ was slowly introduced over $1 \mathrm{~h}$ into the solution via a syringe pump by using a syringe fitted with a $\mathrm{CaCl}_{2}$ guard. The reaction mixture was then stirred at $0{ }^{\circ} \mathrm{C}$ for $1 \mathrm{~h}$. A solution of $\mathrm{I}_{2}(330 \mathrm{mg}, 1.3 \mathrm{mmol})$ in THF $(1 \mathrm{~mL})$ was then added at the same temperature, and the mixture was stirred for $1 \mathrm{~h}$. $\mathrm{CH}_{2} \mathrm{Cl}_{2}(10 \mathrm{~mL})$ followed by an aqueous solution of $\mathrm{Na}_{2} \mathrm{~S}_{2} \mathrm{O}_{3}(10 \%)$ were added. The layers were separated, the aqueous one being extracted with $\mathrm{CH}_{2} \mathrm{Cl}_{2}$ $(2 \times 10 \mathrm{~mL})$. The combined organic layers were washed with $\mathrm{HCl}(1 \mathrm{M})(10 \mathrm{~mL})$ and brine $(10 \mathrm{~mL})$, dried over $\mathrm{MgSO}_{4}$, and concentrated under reduced pressure. Purification by flash chromatography on silica gel (pentane/ether 80:20) afforded the title compound 16 (46 mg, 64\%) as a pale yellow oil. IR (neat): 2947, 2878, 1730, 1630, 1432, 1236, 1081, $941 \mathrm{~cm}^{-1}$; ${ }^{1} \mathrm{H}$ NMR $\left(400 \mathrm{MHz}, \mathrm{CDCl}_{3}\right) \delta 4.32(\mathrm{~d}(\mathrm{AB}$ system $), J=14.0 \mathrm{~Hz}, 1 \mathrm{H})$, 4.27 (d(AB system), $J=14.0 \mathrm{~Hz}, 1 \mathrm{H}), 4.24$ (d(AB system), $J=$ $8.8 \mathrm{~Hz}, 1 \mathrm{H}), 4.15$ (d(AB system), $J=8.8 \mathrm{~Hz}, 1 \mathrm{H}), 3.75$ (s, 3H), $2.21(\mathrm{~m}, 1 \mathrm{H}), 1.95(\mathrm{~m}, 1 \mathrm{H}), 0.98(\mathrm{t}, J=7.5 \mathrm{~Hz}, 3 \mathrm{H}) ;{ }^{13} \mathrm{C} \mathrm{NMR}$ $\left(100 \mathrm{MHz}, \mathrm{CDCl}_{3}\right) \delta 172.4,152.4,80.1,79.5,60.9,52.8,41.2$, $25.5,9.0$; HRMS-ESI $(\mathrm{m} / z):[\mathrm{M}+\mathrm{Na}]^{+}$calcd for $\mathrm{C}_{9} \mathrm{H}_{12} \mathrm{O}_{3} \mathrm{BrINa}$ : 396.89067; found: 396.89159 .

(Z)-Methyl 4-(bromoiodomethylene)-3-isobutyltetrahydrofuran-3-carboxylate (17) (Table 3, entry 4): The title compound was obtained as a side-product following the abovedescribed procedure for the preparation of $(E)$-4ad. It could not be isolated pure after column chromatography, but characteristic NMR spectroscopic data were obtained. ${ }^{1} \mathrm{H}$ NMR $\left(400 \mathrm{MHz}, \mathrm{CDCl}_{3}\right) \delta 4.32(\mathrm{~d}(\mathrm{AB}$ system $), J=14.0 \mathrm{~Hz}, 1 \mathrm{H})$, 4.29 (d(AB system), $J=14.0 \mathrm{~Hz}, 1 \mathrm{H}), 4.24$ (d(AB system), $J=$ $8.9 \mathrm{~Hz}, 1 \mathrm{H}), 4.21$ (d(AB system), $J=8.9 \mathrm{~Hz}, 1 \mathrm{H}), 3.75$ (s, 3H), $2.10(\mathrm{dd}, J=14.5,6.8 \mathrm{~Hz}, 1 \mathrm{H}), 1.95(\mathrm{dd}, J=14.5,5.0 \mathrm{~Hz}, 1 \mathrm{H})$, $1.81(\mathrm{~m}, 1 \mathrm{H}), 0.98(\mathrm{~d}, J=6.7 \mathrm{~Hz}, 3 \mathrm{H}), 0.95(\mathrm{~d}, J=6.6 \mathrm{~Hz}, 3 \mathrm{H})$; ${ }^{13} \mathrm{C} \mathrm{NMR}\left(100 \mathrm{MHz}, \mathrm{CDCl}_{3}\right) \delta 172.5,152.9,80.3,79.8,58.3$, $52.7,41.9,40.7,24.7,24.5,23.8$.

\section{References}

1. Bazin, S.; Feray, L.; Bertrand, M. P. Chimia 2006, 60, 260-265.

2. Akindele, T.; Yamada, K.-i.; Tomioka, K. Acc. Chem. Res. 2009, 42, 345-355. doi:10.1021/ar800166q

3. Seyferth, D. Organometallics 2001, 20, 2940-2955. doi:10.1021/om010439f
4. Cohen, T.; Gibney, H.; Ivanov, R.; Yeh, E. A.-H.; Marek, I.; Curran, D. P. J. Am. Chem. Soc. 2007, 129, 15405-15409. doi:10.1021/ja076554k

5. Lewiński, J.; Marciniac, W.; Lipkowski, J.; Justyniak, I. J. Am. Chem. Soc. 2003, 125, 12698-12699. doi:10.1021/ja036020t

6. Lewiński, J.; Śliwiński, W.; Dranka, M.; Justyniak, I.; Lipkowski, J. Angew. Chem., Int. Ed. 2006, 45, 4826-4829. doi:10.1002/anie.200601001

7. Lewiński, J.; Suwała, K.; Kubisiak, M.; Ochal, Z.; Justyniak, I.; Lipkowski, J. Angew. Chem., Int. Ed. 2008, 47, 7888-7889. doi:10.1002/anie.200803254

8. Lewiński, J.; Bury, W.; Dutkiewicz, M.; Maurin, M.; Justyniak, I.; Lipkowski, J. Angew. Chem., Int. Ed. 2008, 47, 573-576. doi:10.1002/anie.200703125

9. Lewiński, J.; Kościelski, M.; Suwała, K.; Justyniak, I. Angew. Chem., Int. Ed. 2009, 48, 7017-7020. doi:10.1002/anie.200902716

10. Lewiński, J.; Suwała, K.; Kaczorowski, T.; Gałęzowski, M.; Gryko, D. T.; Justyniak, I.; Lipkowski, J. Chem. Commun. 2009, 215-217. doi:10.1039/b813315h

11. Jana, S.; Berger, R. J. F.; Fröhlich, R.; Pape, T.; Mitzel, N. W. Inorg. Chem. 2007, 46, 4293-4297. doi:10.1021/ic062438r

12. Mileo, E.; Benfatti, F.; Cozzi, P. G.; Lucarini, M. Chem. Commun. 2009, 469-470. doi:10.1039/b818437b

13. Maury, J.; Feray, L.; Bazin, S.; Clément, J.-L.; Marque, S. R. A.; Siri, D.; Bertrand, M. P. Chem.-Eur. J. 2011, 17, 1586-1595. doi:10.1002/chem.201002616

14. Mukherjee, D.; Ellern, A.; Sadow, A. D. J. Am. Chem. Soc. 2012, 134, 13018-13026. doi:10.1021/ja303440n

15. Bertrand, M. P.; Feray, L.; Nouguier, R.; Perfetti, P. J. Org. Chem. 1999, 64, 9189-9193. doi:10.1021/jo9912404

16. Bazin, S.; Feray, L.; Siri, D.; Naubron, J.-V.; Bertrand, M. P. Chem. Commun. 2002, 2506-2507. doi:10.1039/b206695e

17. Bazin, S.; Feray, L.; Vanthuyne, N.; Bertrand, M. P. Tetrahedron 2005, 61, 4261-4274. doi:10.1016/j.tet.2005.02.042

18. Bazin, S.; Feray, L.; Vanthuyne, N.; Siri, D.; Bertrand, M. P. Tetrahedron 2007, 63, 77-85. doi:10.1016/j.tet.2006.10.049

19. Maury, J.; Feray, L.; Perfetti, P.; Bertrand, M. P. Org. Lett. 2010, 12, 3590-3593. doi:10.1021/ol101519w

20. Maury, J.; Mouysset, D.; Feray, L.; Marque, S. R. A.; Siri, D.; Bertrand, M. P. Chem.-Eur. J. 2012, 18, 3241-3247. doi:10.1002/chem.201102366

21. Van der Deen, H.; Kellog, R. M.; Feringa, B. L. Org. Lett. 2000, 2, 1593-1595. doi:10.1021/ol005843+

22. Miyabe, H.; Asada, R.; Yoshida, K.; Takemoto, Y. Synlett 2004, 540-542. doi:10.1055/s-2004-815407

23. Miyabe, H.; Asada, R.; Takemoto, Y. Tetrahedron 2005, 61, 385-393. doi:10.1016/j.tet.2004.10.104

24. Yamada, K.-i.; Umeki, M.; Maekawa, M.; Yamamoto, Y.; Akindele, T.; Nakano, M.; Tomioka, K. Tetrahedron 2008, 64, 7258-7265. doi:10.1016/j.tet.2008.05.069

25. Yamada, K.-i.; Konishi, T.; Nakano, M.; Fujii, S.; Cadou, R.; Yamamoto, Y.; Tomioka, K. J. Org. Chem. 2012, 77, 5775-5780. doi:10.1021/jo300944f

26. Cozzi, P. G. Angew. Chem., Int. Ed. 2006, 45, 2951-2954. doi:10.1002/anie.200504239

27. Cozzi, P. G. Adv. Synth. Catal. 2006, 348, 2075-2079. doi:10.1002/adsc.200606178

28. Cozzi, P. G.; Mignogna, A.; Vicennati, P. Adv. Synth. Catal. 2008, 350 , 975-978. doi:10.1002/adsc.200700572 
29. Fernández-lbáñez, M. A.; Maciá, B.; Minnaard, A. J.; Feringa, B. L. Angew. Chem., Int. Ed. 2008, 47, 1317-1319. doi:10.1002/anie.200704841

30. Cozzi, P. G.; Benfatti, F.; Guiteras Capdevila, M.; Mignogna, A. Chem. Commun. 2008, 3317-3318. doi:10.1039/b805197f

31. Pérez-Luna, A.; Botuha, C.; Ferreira, F.; Chemla, F. New J. Chem. 2008, 32, 594-606. doi:10.1039/b716292h

32. Denes, F.; Chemla, F.; Normant, J. F. Angew. Chem., Int. Ed. 2003, 42, 4043-4046. doi:10.1002/anie.200250474

33. Denes, F.; Cutri, S.; Pérez-Luna, A.; Chemla, F. Chem.-Eur. J. 2006, 12, 6506-6513. doi:10.1002/chem.200600334

34. Denes, F.; Pérez-Luna, A.; Chemla, F. J. Org. Chem. 2007, 72, 398-406. doi:10.1021/jo061603h

35. Giboulot, S.; Pérez-Luna, A.; Botuha, C.; Ferreira, F.; Chemla, F. Tetrahedron Lett. 2008, 49, 3963-3966. doi:10.1016/j.tetlet.2008.04.108

36. Feray, L.; Bertrand, M. P. Eur. J. Org. Chem. 2008, 3164-3170. doi:10.1002/ejoc.200800242

37. Pérez-Luna, A.; Botuha, C.; Ferreira, F.; Chemla, F. Chem.-Eur. J. 2008, 14, 8784-8788. doi:10.1002/chem.200801451

38. Chemla, F.; Dulong, F.; Ferreira, F.; Nüllen, M.; Pérez-Luna, A. Synthesis 2011, 1347-1360. doi:10.1055/s-0030-1259993

39. Chen, Z.; Zhang, Y.-X.; An, Y.; Song, X.-L.; Wang, Y.-H.; Zhu, L.-L.; Guo, L. Eur. J. Org. Chem. 2009, 5146-5152. doi:10.1002/ejoc.200900858

40. Maury, J.; Feray, L.; Bertrand, M. P. Org. Lett. 2011, 13, 1884-1887. doi:10.1021/ol200419x

41. Stüdemann, T.; Knochel, P. Angew. Chem., Int. Ed. Engl. 1997, 36, 93-95. doi:10.1002/anie.199700931

42. Stüdemann, T.; Ibrahim-Ouali, M.; Knochel, P. Tetrahedron 1998, 54, 1299-1316. doi:10.1016/S0040-4020(97)10226-5

43. Gourdet, B.; Lam, H. W. J. Am. Chem. Soc. 2009, 131, 3802-3803. doi:10.1021/ja900946h

44. Normant, J. F.; Alexakis, A. Synthesis 1981, 841-870. doi:10.1055/s-1981-29622

45. Chinkov, N.; Tene, D.; Marek, I. In Metal-Catalyzed Cross Coupling Reactions, 2nd ed.; Diederich, D.; de Meijere, A., Eds.; Wiley-VCH: New York, 2004; p 395.

46. Denès, F.; Pérez-Luna, A.; Chemla, F. Chem. Rev. 2010, 110, 2366-2447. doi:10.1021/cr800420x

47. Marek, I. Chem. Rev. 2000, 100, 2887-2900. doi:10.1021/cr990288e

48. Harada, T.; Katsuhira, T.; Oku, A. J. Org. Chem. 1992, 57, 5805-5807. doi:10.1021/jo00048a002

49. Harada, T.; Katsuhira, T.; Hara, D.; Kotani, Y.; Maejima, K.; Kaji, R.; Oku, A. J. Org. Chem. 1993, 58, 4897-4907. doi:10.1021/jo00070a027

50. Harada, T.; Katsuhira, T.; Hattori, K.; Oku, A. Tetrahedron 1994, 50, 7987-8002. doi:10.1016/S0040-4020(01)85284-4

51. Creton, I.; Marek, I.; Normant, J.-F. Synthesis 1996, 1499-1508. doi:10.1055/s-1996-4422

52. Deng, C.-L.; Song, R.-J.; Liu, Y.-L.; Li, J.-H. Adv. Synth. Catal. 2009, 351, 3096-3100. doi:10.1002/adsc.200900588

The $\mathrm{ZnCl}_{2}$ catalyzed Conia-ene reaction of iodoalkynes that in principle involves a vinylidene zinc carbenoid intermediate has been reported here.

53. The $Z$ configuration for the major isomer was determined by NOE experiments on isolated pure (Z)-4aa. An NOE signal (3\%) was observed between the vinylic proton and the protons of the methylene group of the propyl chain a to the ester.

54. Yeh, M. C. P.; Knochel, P. Tetrahedron Lett. 1989, 30, 4799-4802. doi:10.1016/S0040-4039(01)80511-6
55. Creton, I.; Rezaei, H.; Marek, I.; Normant, J. F. Tetrahedron Lett. 1999, 40, 1899-1902. doi:10.1016/S0040-4039(99)00090-8

56. Rezaei, H.; Marek, I.; Normant, J. F. Tetrahedron 2001, 57, 2477-2483. doi:10.1016/S0040-4020(01)00069-2

57. Rezaei, H.; Yamanoi, S.; Chemla, F.; Normant, J. F. Org. Lett. 2000, 2, 419-421. doi:10.1021/ol991117z

58. Fallis, A. G.; Forgione, P. Tetrahedron 2001, 57, 5899-5913. doi:10.1016/S0040-4020(01)00422-7

59. Takahashi, K.; Honda, T. Org. Lett. 2010, 12, 3026-3029. doi:10.1021/ol101034s

$\mathrm{Zn}$-atom radical transfer is facilitated by coordination to a Lewis base. In the present case, the bromine atom may be coordinated to the dialkylzinc reagent and thereby activates it towards homolytic substitution. For a similar proposed coordination involving $\mathrm{Sml}_{2}$, see this reference.

60. Even though the $\mathrm{H}$-donor has not been identified, competitive $\mathrm{H}$-atom transfer is a frequent side-reaction in the 1,4-addition/cyclization reaction of dialkylzincs with $\beta$-(propargyloxy)enoates, see references [37] and [38].

61. The stereochemical assignment was done on the basis of the comparison of the NMR data of 4ac and 4aa. Among others, the chemical shift $(\delta=6.17 \mathrm{ppm})$ and coupling constant of the vinylic proton $(J=1.9 \mathrm{~Hz})$ are indicative of the $E$-configuration.

\section{License and Terms}

This is an Open Access article under the terms of the Creative Commons Attribution License (http://creativecommons.org/licenses/by/2.0), which permits unrestricted use, distribution, and reproduction in any medium, provided the original work is properly cited.

The license is subject to the Beilstein Journal of Organic Chemistry terms and conditions:

(http://www.beilstein-journals.org/bjoc)

The definitive version of this article is the electronic one which can be found at: doi:10.3762/bjoc. 9.28 